\title{
Sound production by red hind Epinephelus guttatus in spatially segregated spawning aggregations
}

\author{
David Mann ${ }^{1, *}$, James Locascio' ${ }^{1}$, Michelle Schärer ${ }^{2}$, Michael Nemeth², \\ Richard Appeldoorn ${ }^{2}$
}

\author{
${ }^{1}$ University of South Florida, College of Marine Science, 140 7th Avenue South, St. Petersburg, Florida 33701, USA \\ ${ }^{2}$ University of Puerto Rico, Department of Marine Science, PO Box 9000, Mayagüez, Puerto Rico 00681
}

\begin{abstract}
Many fishes, including groupers, produce sounds associated with mating behavior; recording and analyzing the occurrence of these sounds can provide long time-series records of grouper use of spawning habitat. Red hind Epinephelus guttatus sound production was recorded on spawning aggregation sites off the west coast of Puerto Rico and at Mona Island, Puerto Rico. Audiovideo recordings were used to identify a species-specific sound produced by male red hind, most commonly during territorial patrols, and also during interactions with females. This sound is low in frequency (50 to $400 \mathrm{~Hz}$ ) and consists of a series of pulses repeated at a variable rate. Long-term acoustic recorders were placed off the west coast of Puerto Rico at Abrir La Sierra and at Mona Island to record the timing of red hind sound production from January through March. Red hind sounds were detected at all times of the day, with peaks in sound production just before dusk. Monthly peaks in sound production were evident in each time series, but the monthly peak in sound production at Abrir La Sierra was 6 d later than the peak at Mona Island, suggesting that the timing of spawning of these 2 aggregations, while on a lunar schedule, was not broadly synchronized during this time period. This research lays the groundwork for both long-term monitoring and mapping of red hind spawning sites that will be useful for managing spawning aggregations, especially in remote areas.
\end{abstract}

KEY WORDS: Red hind · Spawning aggregation $\cdot$ Sound production $\cdot$ Mona Island $\cdot$ Puerto Rico

\section{INTRODUCTION}

The red hind Epinephelus guttatus is a protogynous hermaphrodite grouper that forms yearly spawning aggregations (Shapiro et al. 1993, 1994, Sadovy et al. 1994). These spawning aggregations have been targeted by fishers in the past, and this led to dramatic declines in the number of fishes and to a female bias in the sex ratio due to the capture of larger-sized males. Areas closed to fishing in the US Virgin Islands have resulted in an increase in the size of the red hind as well as a decrease in the female bias of the sex ratio (Beets \& Friedlander 1999, Nemeth 2005). Monitoring the level of spawning activity at aggregation sites for extended periods of time can be used to document the level of population recovery and effectiveness of fisheries management.
Fish sound production, including that of red hind, has long been known (Tavolga 1968, Fish \& Mowbray 1970). Most fish sounds are species-specific in frequency and pulse rate, which allows their presence to be detected from acoustic recordings (e.g. Connaughton \& Taylor 1996, Mann et al. 1997, Zelick et al. 1999). Some pioneering studies (e.g. Breder 1968) showed the promise of passive acoustics for studying fish behavior over seasonal time scales. Passive acoustics has grown recently with improvements in computer systems for acquiring passive acoustic data and processing these data sets. For example, studies on spawning haddock and sciaenids (e.g. red drum, spotted seatrout) show that passive acoustics can be used to record data that would otherwise be difficult to obtain (Mok \& Gilmore 1983, Saucier \& Baltz 1993, Mann \& Lobel 1995, Luczkovich et al. 1999, Gilmore 2003). 
Red hind were recorded by Tavolga (1968) and Fish \& Mowbray (1970) as part of a survey of sounds produced by fishes. In their studies, red hind were found to produce low-frequency pulsed sounds with most of the energy below $200 \mathrm{~Hz}$. These sounds were recorded from captive specimens, and were likely defensive sounds associated with being handled. It is possible that the sounds recorded in captivity were not representative of the sounds that might be produced by aggregating red hind, as has been observed for many sciaenids. The goals of the present study were to record and characterize sounds from wild red hind on known spawning aggregation sites and to document long-term patterns of sound production from daily to monthly time scales at 2 sites separated by deep water in Puerto Rico during the red hind spawning season.

\section{MATERIALS AND METHODS}

Underwater video recordings. Underwater audiovideo recordings of red hind behavior were conducted by SCUBA divers at Mona Island, Puerto Rico, using Sony PC-110 and SR80 video cameras. Each camera was housed in an Ocean Images underwater video housing and connected to an HTI 96-min hydrophone (sensitivity $2 \mathrm{~Hz}$ to $37 \mathrm{kHz}_{;}-164 \pm 1 \mathrm{dBV} \mu \mathrm{Pa}^{-1}$ ). Recordings were made from January to March 2007 during dives from 16:00 $\mathrm{h}$ through dusk. The video recordings were used to record red hind behavior and associated sound production. The audio portion of the recordings was only used for descriptive purposes and to identify species-specific sounds. Because of the automatic gain control and audio compression used by the digital recorders, detailed acoustic analyses of red hind sounds were conducted with recordings made using audio recorders as described below.

Long-term acoustic recordings. Longterm acoustic recording systems (LARS; Loggerhead Instruments; disclosure: D. Mann is an owner of Loggerhead Instruments) were used to document patterns of red hind sound production from January to March 2007. Each LARS consisted of a Toshiba E755 Pocket PC in an underwater aluminum housing connected to a hydrophone (HTI 96-min; sensitivity 0 to $37 \mathrm{kHz}$; $\left.-164 \mathrm{dBV} \mu \mathrm{Pa}^{-1}\right)$. The hydrophone signal was digitized at $44.1 \mathrm{kHz}$, then low-pass filtered and decimated to a $4410 \mathrm{~Hz}$ sample rate by onboard software. The signals were stored as wav files to 2 GB compact flash cards. Signals were digitized for $20 \mathrm{~s}$ every $5 \mathrm{~min}$. The LARS were mounted on concrete tiles on the sea bottom.

Recorders were deployed on the west coast of Puerto Rico at Abrir La Sierra (Cabo Rojo), a site known to have a spawning aggregation of red hind at a depth of $30 \mathrm{~m}$. Recorders were also deployed at a red hind aggregation site at Mona Island, Puerto Rico, at depths ranging from 20 to $30 \mathrm{~m}$. These 2 sites are located $70 \mathrm{~km}$ apart and are separated by the deep waters of the Mona Channel (Fig. 1). The recorders were downloaded monthly and redeployed during the spawning season.

LARS signal processing. The LARS recordings were analyzed with custom MATLAB software (QLOGGER) that calculates received sound levels in $100 \mathrm{~Hz}$-wide frequency bands. The software calculates the band level ( $\mathrm{dB}$ re $1 \mu \mathrm{Pa}$ ) in the 100 to $200 \mathrm{~Hz}$ frequency band by performing a fast Fourier transform (FFT) on each $20 \mathrm{~s}$ file with a rectangular window (FFT length $=88200$ points). This resulted in time series with average sound levels every $5 \mathrm{~min}$. The maximum sound level for each day from 14:00 to 24:00 $\mathrm{h}$ in the 100 to $200 \mathrm{~Hz}$ band was then calculated.

Individual red hind calls with high signal-to-noise ratios (calls where the pulses could easily be observed in the time domain) were also extracted from the wav file recordings and analyzed to determine the duration, peak frequency and bandwidth. The frequency analyses of these individual calls were performed with $5 \mathrm{~Hz}$ resolution. Duration was manually measured from the time domain signals from the start of the first pulse to the end of the call using a custom MATLAB program called HotWav, which filtered the signals between 10 and $1000 \mathrm{~Hz}$ to improve the signal-to-noise ratio.

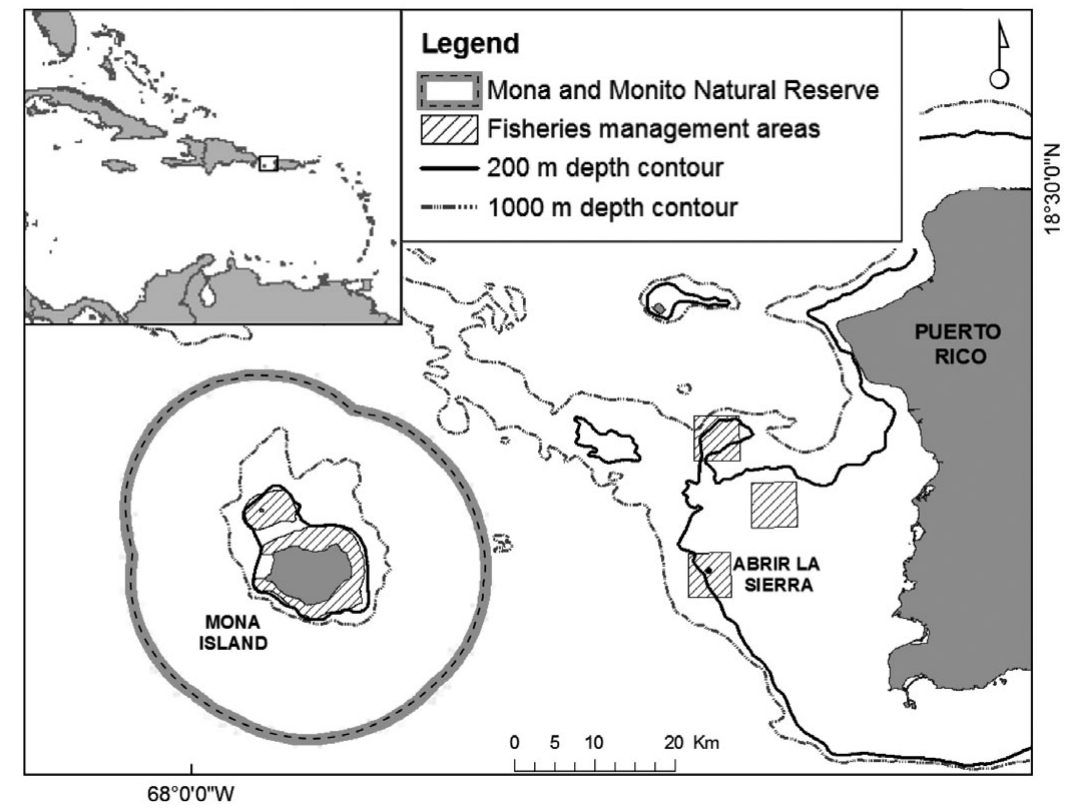

Fig. 1. Study sites on the west coast of Puerto Rico and Mona Island 


\section{RESULTS}

\section{Red hind behavior}

Male red hind developed pronounced pigmentation and displayed changes in color patterns on the spawning aggregation sites. Males commonly swam patrols across their putative territories, and often produced a pulsed sound during these patrols (Fig. 2). In most cases these sounds did not appear to be directed at any particular fish. Sounds were also recorded during male interactions with females (identified as females by their gravid abdomen). These interactions were not as common as the male patrols. Interactions with females did not always involve sound production, and several females were often observed near the bottom within the territory of an individual male.

Male-male interactions took place at apparent edges between male territories. These often involved one fish opening its mouth and placing it on the opercle of the other fish, and many of the male fish showed evidence of wounds associated with these interactions. The males often developed a light colored pattern on their cranio-dorsal surface during these interactions, which typically lasted for about $10 \mathrm{~s}$. Typically, no sounds were produced during these interactions. Occasionally, short pulses were produced.

\section{Red hind sounds}

A total of 67 high signal-to-noise ratio red hind sounds from the LARS from Mona Island were analyzed to provide a quantitative description of the sounds. The sound was not strictly stereotyped. It consisted of a variable number of pulses, and one or more portions of the call had a high pulse rate, which appears tonal (Fig. 2). Sound duration was $1.78 \pm 1.02 \mathrm{~s}$ $($ mean $\pm \mathrm{SE}$ ) and the peak frequency was $166 \pm 36 \mathrm{~Hz}$ (Fig. 3). The $3 \mathrm{~dB}$ bandwidth was $46.6 \pm 20.6 \mathrm{~Hz}$. An additional 19 sounds from Abrir La Sierra were analyzed and showed an overlapping distribution with those from Mona Island. The average sound duration was $1.04 \pm 0.63 \mathrm{~s}($ minimum $=0.63 \mathrm{~s}$, maximum $=3.0 \mathrm{~s}$ ), the peak frequency was $213 \pm 23 \mathrm{~Hz}$ (minimum = $130 \mathrm{~Hz}$, maximum $=250 \mathrm{~Hz}$ ) and the $3 \mathrm{~dB}$ bandwidth was $38.2 \pm 18.5 \mathrm{~Hz}$.

\section{Diel and monthly timing of sound production}

Red hind sounds were recorded at all times of the day and night, but sound production peaked near dusk. Analysis of sound levels in the 100 to $200 \mathrm{~Hz}$ band showed diel peaks in sound production in the
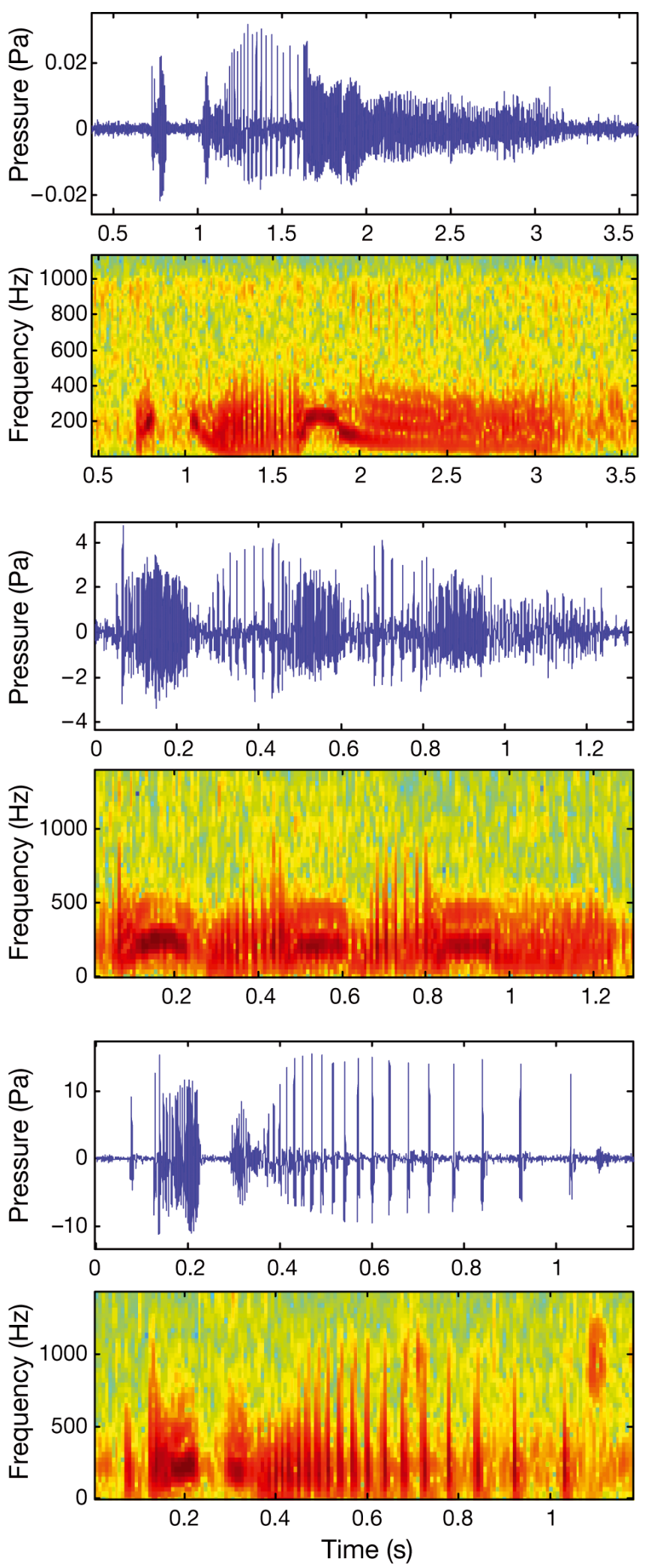

Fig. 2. Epinephelus guttatus. Examples of 3 red hind sounds. Sounds are shown as paired oscillograms (top of pair) and spectrograms (bottom of pair) of the same sound (FFT size $=256$ points, no overlap). Green indicates low, dark red is high sound intensity 
time series (Fig. 4). These diel peaks were consistent between Abrir La Sierra and Mona Island (Fig. 5). Monthly peaks in sound production were evident at both sites (Fig. 5). These monthly peaks had higher levels of calling at all times of day (not only during the dusk period) compared to other times of the month. However, the monthly peaks were earlier in the month at Mona Island than at Abrir La Sierra in both January and February (Fig. 5).

\section{DISCUSSION}

Red hind males make a unique sound on spawning aggregation sites as part of territorial patrolling and courtship behaviors. This sound, which we dubbed the 'whoot-woo', consisted of a series of pulses repeated at variable rates that lasted up to $5 \mathrm{~s}$ in duration. It is different from the sound reported by Fish \& Mowbray (1970), which consisted of single pulses produced during handling. It was also different from the field recording reported by Tavolga (1968), which was a short (100 to $300 \mathrm{~ms}$ ) grunt-like sound. The whoot-woo
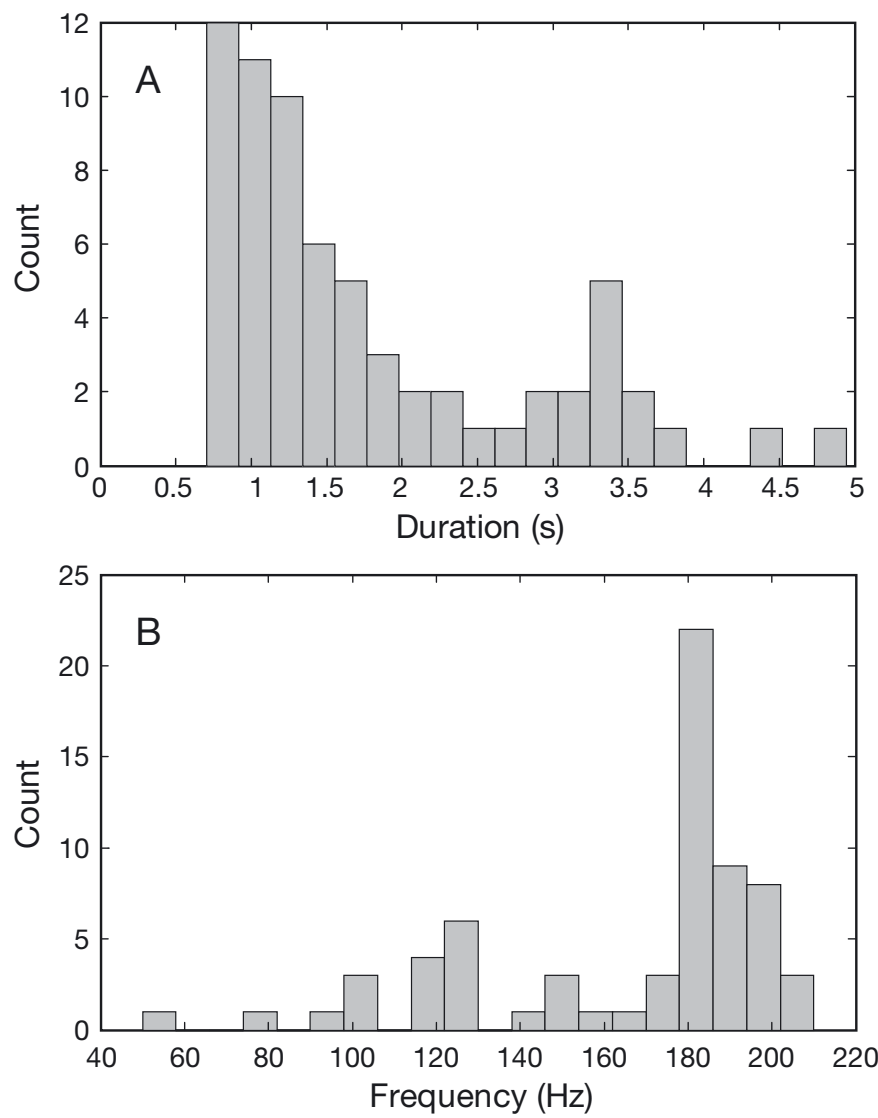

Fig. 3. Epinephelus guttatus. Characterization of red hind sounds from long-term acoustic recorders. (A) Call duration. (B) Peak frequency sound that we recorded was also produced during male-female interactions, but not during male-male interactions.

No spawning was observed during these dives, which took place during periods of peak levels of sound production. We suspect that spawning took place after sunset because gravid females were observed during dusk dives but not on dives conducted the following morning. Analysis of sounds recorded during these nights did not yield any sounds that were distinct from the sounds recorded during the day.

Sound production varied over diel and monthly cycles. While the diel variability was similar between Abrir La Sierra and Mona Island, the monthly variation was not the same. This is a surprising result, since red hind appear to spawn on a lunar cycle. Red hind migrate over large distances on a lunar cycle and are likely synchronized by environmental cues (Nemeth et al. 2007). The acoustic data from the present study show that 2 populations of the same species can have different spawning cycles, perhaps due to geographical separation. Future studies should collect a suite of environmental data including temperature, light levels
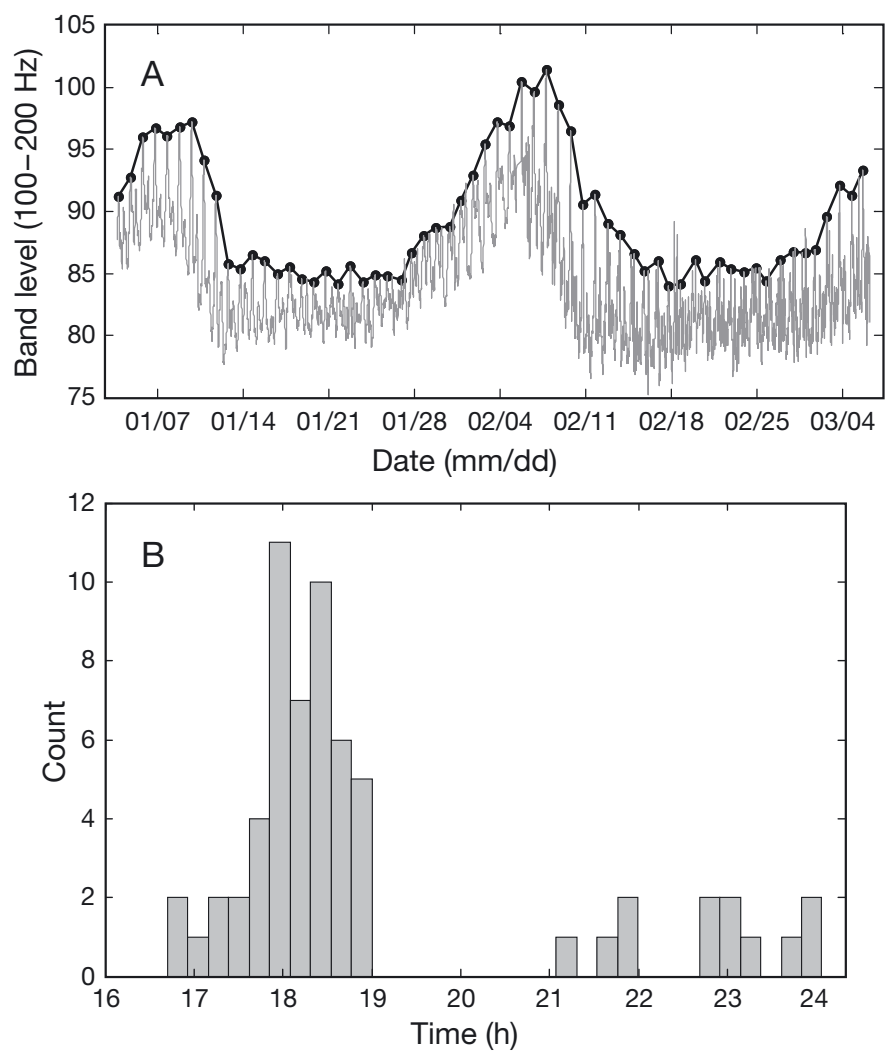

Fig. 4. Epinephelus guttatus. (A) Time series of sound production at Mona Island, Puerto Rico. Grey line is the 3-point moving average smoothing of band level (100 to $200 \mathrm{~Hz}$; dB re $1 \mu \mathrm{Pa}$ ) sound. Black dots and line indicate daily peak sound production. (B) Histogram of time of maximum daily sound production at Mona Island 

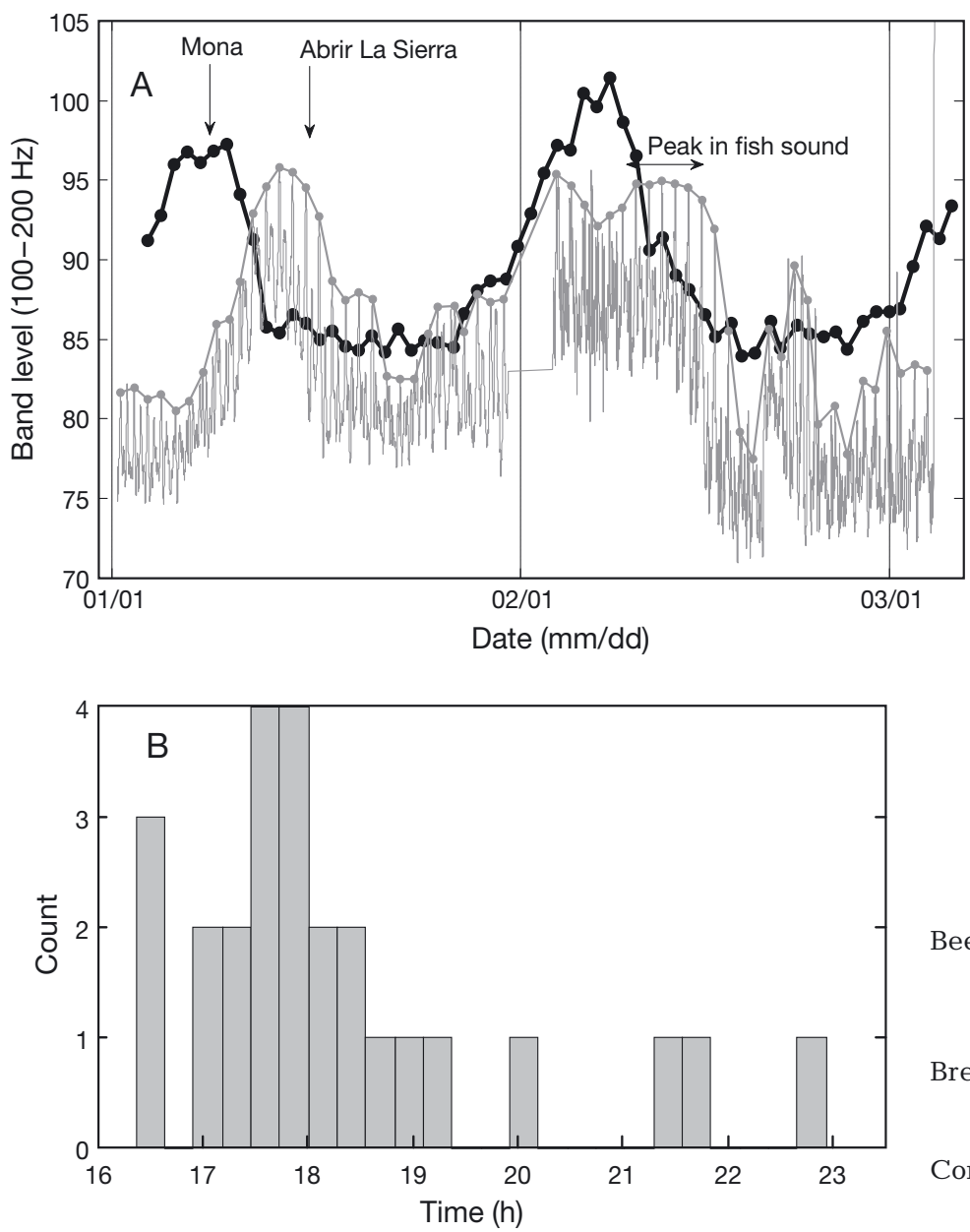

Fig. 5. Epinephelus guttatus. (A) Time series of sound production (band level from 100 to $200 \mathrm{~Hz}$; dB re $1 \mu \mathrm{Pa}$ ) at Abrir La Sierra and Mona Island from January to March 2007. Time series from Mona only shows daily peaks in sound levels. The first few days of the deployment at Abrir La Sierra in February are contaminated by noise. The peak in sound production occurred 7 to $10 \mathrm{~d}$ after the February deployment started (double arrow). (B) Time of peak sound production at Abrir La Sierra; only peaks that could be clearly identified as fish sound production were included

and currents, and include more study sites over a longer period of time (although spawning aggregation areas are limited) to try to determine the source of this apparent spatial variability.

The results from the present study demonstrate that passive acoustics is a promising technique for mapping red hind aggregation sites over large spatial scales and for long-term monitoring of aggregations. The red hind has been the focus of protected areas and seasonal closures in the US Virgin Islands and Puerto Rico. There are many areas that could contain aggregations of red hind that have not yet been identified. Passive acoustics provides a relatively inexpensive means to map red hind sound production over large spatial scales, either through the deployment of large numbers of recorders or towing hydrophone arrays to listen for red hind sounds. Acoustic recorders with yearly maintenance schedules could also be developed to simultaneously monitor protected areas for long time periods at remote sites. This is much more cost effective than performing repeated dives at the same location, and has the added benefit of being able to detect the acoustic signature of motor boats that may be illegally fishing at the closed sites.

Acknowledgements. We thank P. Simard, B. Nichols, W. Dent and F. García-Huertas for help with diving. We also thank the crew of the RV 'Orca Too' for support during field expeditions. This publication is a result of funding from the National Oceanic and Atmospheric Administration, Center for Sponsored Coastal Ocean Research, under award no. NA05NOS4261159 to the University of Puerto Rico for the Caribbean Coral Reef Institute.

\section{LITERATURE CITED}

Beets J, Friedlander A (1999) Evaluation of a conservation strategy: a spawning aggregation closure for red hind, Epinephelus guttatus, in the U.S. Virgin Islands. Environ Biol Fishes 55:91-98

Breder CM (1968) Seasonal and diurnal occurrences of fish sounds in a small Florida bay. Bull Am Mus Nat Hist $138: 327-378$

Connaughton MA, Taylor MH (1996) Drumming, courtship, and spawning behavior in captive weakfish, Cynoscion regalis. Copeia 1996:195-199

Fish MP, Mowbray WH (1970) Sounds of western North Atlantic fishes. A reference file of biological underwater sounds. The John Hopkins Press, Baltimore, MD

Gilmore RG (2003) Sound production and communication in the spotted seatrout. In: Bortone SA (ed) Biology of the spotted seatrout. CRC Press, Boca Raton, FL, p 177-195

Luczkovich JJ, Sprague MW, Johnson SE, Pullinger RC (1999) Delimiting spawning areas of weakfish, Cynoscion regalis (family Sciaenidae), in Pamlico Sound, North Carolina using passive hydroacoustic surveys. Bioacoustics 10: $143-160$

Mann DA, Lobel PS (1995) Passive acoustic detection of sounds produced by the damselfish Dascyllus albisella (Pomacentridae). Bioacoustics 6:199-213

Mann DA, Bowers-Altman J, Rountree RA (1997) Sounds produced by the striped cusk eel, Ophidion marginatum, during courtship and spawning. Copeia 610-612

Mok HK, Gilmore RG (1983) Analysis of sound production in estuarine aggregations of Pogonias cromis, Bairdiella chrysoura, and Cynoscion nebulosus (Sciaenidae). Bull Inst Zool Acad Sin 22:157-186

Nemeth RS (2005) Population characteristics of a recovering US Virgin Islands red hind spawning aggregation following protection. Mar Ecol Prog Ser 286:81-97

Nemeth RS, Blondeau J, Herzlieb S, Kadison E (2007) Spatial and temporal patterns of movement and migration at spawning aggregations of red hind, Epinephelus guttatus, in the U.S. Virgin Islands. Environ Biol Fishes 78:365-381

Sadovy Y, Rosario A, Román A (1994) Reproduction in an 
aggregating grouper, the red hind, Epinephelus guttatus. Environ Biol Fishes 41:269-286

Saucier MH, Baltz DM (1993) Spawning site selection by spotted seatrout, Cynoscion nebulosus, and black drum, Pogonias cromis, in Louisiana. Environ Biol Fishes 36:257-272

Shapiro DY, Sadovy Y, McGehee MA (1993) Size, composition, and spatial structure of the annual spawning aggregation of the red hind, Epinepehlus guttatus. Copeia 1993:399-406

Shapiro DY, García-Moliner G, Sadovy Y (1994) Social system

Editorial responsibility: Hans Heinrich Janssen,

Oldendorf/Luhe, Germany of an inshore stock of the red hind grouper, Epinephelus guttatus (Pisces: Serranidae). Environ Biol Fishes 41: 415-422

Tavolga WN (1968) Marine animal data atlas. Tech Rep NAVTRADEVCEN 1212-2, American Museum of Natural History, New York

Zelick R, Mann DA, Popper AN (1999) Acoustic communication in fishes and frogs. In: Fay RR, Popper AN (eds) Comparative hearing: fish and amphibians. Springer, New York, p 363-411

Submitted: February 24, 2010; Accepted: July 7, 2010

Proofs received from author(s): August 13, 2010 